\title{
An Update on the Role of Markers of Inflammation in Atherosclerosis
}

\author{
Egle Corrado ${ }^{1}$, Manfredi Rizzo², Giuseppe Coppola ${ }^{1}$, Khalil Fattouch ${ }^{3}$, Giuseppina Novo ${ }^{1}$, \\ Ilenia Marturana ${ }^{1}$, Filippo Ferrara ${ }^{4}$, and Salvatore Novo ${ }^{1}$
}

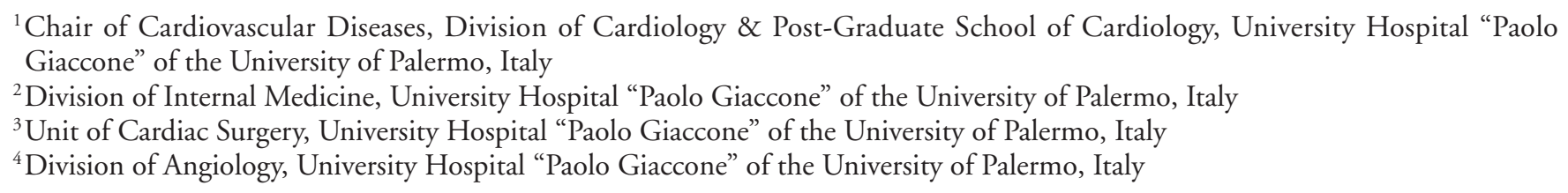

In recent years, several studies have used the measurement of carotid intima-media thickness (IMT) as a marker of early atherosclerosis: IMT has been shown to correlate significantly with the presence of coronary artery disease (CAD) and to predict fatal and not fatal cerebro- and cardio-vascular events. These findings highlight the importance of recognizing and managing early stages of atherosclerosis for effective cardiovascular prevention. Beyond traditional established cardiovascular risk factors, inflammation has been shown to be crucial throughout atherosclerosis from endothelial dysfunction to plaque rupture and thrombosis. Several studies have shown the existence of a strong relation between CAD and fibrinogen or highly sensitive C-reactive protein (hs-CRP) levels and their predictive role has been examined through stratification or multivariable statistical analyses: levels of these markers of inflammation have been independently associated with the incidence of coronary events after adjusting for traditional cardiovascular risk factors. Recent studies have further addressed the importance of therapeutical modulation of hs-CRP levels in high-risk patients for the prevention of vascular events. The strong relationship between hs-CRP and IMT may potentially account for the complex role of hs-CRP and IMT in the pathogenesis of cardiovascular events. However, beyond the utility of measuring markers of inflammation to assess patients with subclinical carotid atherosclerosis at higher risk of vascular events, further studies are needed to evaluate the therapeutic implications in this category of patients.

\section{J Atheroscler Thromb, 2010; 17:1-11.}

Key words; Inflammation, Carotid atherosclerosis, Cardiovascular risk

\section{Introduction}

Atherosclerosis is a high-cost disease and its complications still represent the first cause of death in most industrialized countries. Efficacious prevention includes treatment of the most important cardiovascular risk factors, such as cigarette smoking, hypertension, hypercholesterolemia, diabetes and obesity.

Address for correspondence: Egle Corrado, Division of Cardiology \& Post-Graduate School of Cardiology, University Hospital "Paolo Giaccone" of the University of Palermo, Italy E-mail: egle.corrado@libero.it

Received: April 29, 2009

Accepted for publication: July 2, 2009
However, the absence of such "traditional" risk factors does not completely protect from the disease and new "emerging factors" have been identified, including markers of inflammation ${ }^{1)}$. Observational and epidemiological data have suggested the potential predictive role of fibrinogen and highly sensitive C-reactive protein (hs-CRP) in coronary artery disease (CAD) and the National Cholesterol Education Program, through the Adult Treatment Panel III Guidelines ${ }^{2)}$, identified these agents as "emerging risk factors", suggesting that their measurement may adjust the estimations of absolute risk obtained using traditional cardiovascular risk factors.

C-reactive protein is an hepatically derived pen- 


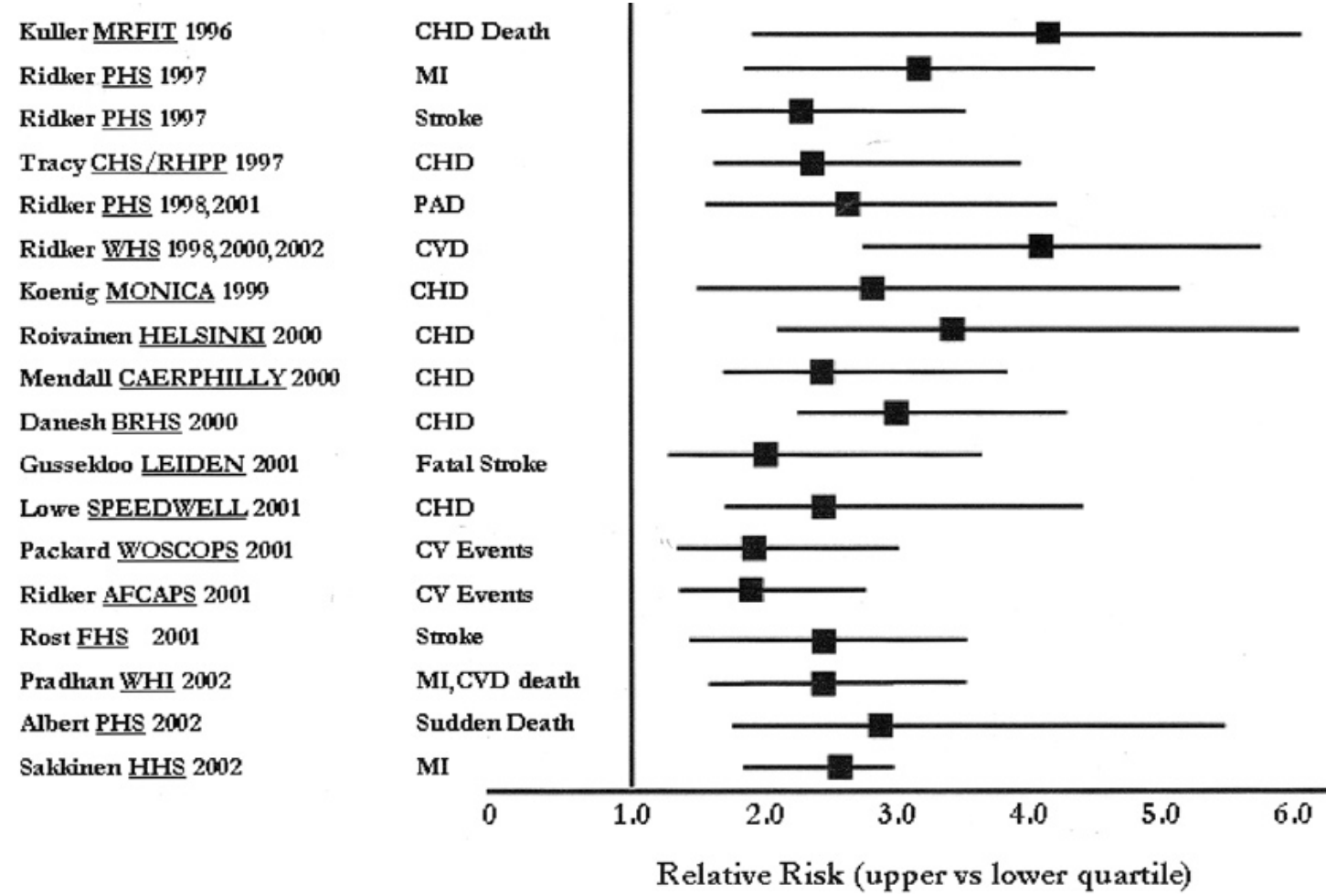

Fig. 1. Prospective studies relating baseline HS-CRP levels to the risk of first cardiovascular events.

(Ridker PM. Circulation, 2003; 107: 363-369)

traxin that plays a key role in the innate immune response. Standard CRP tests determine levels which are increased up to 1,000-fold in response to infection or tissue destruction, but cannot adequately assess the normal range. Highly sensitive CRP (hs-CRP) detects levels ofhs- CRP within the normal range as well as higher levels proven to predict future cardiovascular events. In vitro, hs-CRP has been found to activate a number of processes involved in inflammatory reactions. In human endothelial cells, hs-CRP induces the expression of adhesion molecules VCAM-1, ICAM-1 and E-selectin as well as monocytes chemo-attractant protein-1 (MCP-1). In human monocytes, hs-CRP has been found to stimulate the production of tissue factor, an activator of the extrinsic pathway of the coagulation system ${ }^{3)}$. Available perspective epidemiological studies ${ }^{4)}$, including elderly as well as middleaged individuals, show consistency for the endpoints of first-ever myocardial infarction or stroke as well as for the development of symptomatic peripheral arterial disease (Fig. 1).

In addition, experimental evidence has shown that fibrinogen is involved early in the formation and growth of atheroma infiltrating the arterial wall and it is also a precursor of mural fibrin thrombi, later incor- porated into the arterial wall. Fibrinogen is involved in a number of mechanisms (platelet aggregation, endothelial cell injury, plasma viscosity) that play a central role in the formation of thrombi. Fibrinogen is a substrate leading to the generation of thrombin, the end point of the hemostatic process, and affects blood rheology as well as platelet aggregation, generating a hypercoagulable state that promotes thrombus formation. The importance of hyperfibrinogenemia as a risk factor for atherothrombosis is confirmed by previous studies showing an association between high fibrinogen levels and a) other risk factors for cardiovascular disease, including age, smoking habit, cholesterol, physical inactivity, arterial hypertension, and diabetes; b) angiographically determined number and severity of coronary and extracoronary stenoses; and c) future risk of cardiovascular events such as angina pectoris, myocardial infarction, stroke and sudden death. Metanalysis by Maresca et al. ${ }^{5)}$ demonstrated that the estimated risk of CAD is more than doubled when comparing the highest tertile of fibrinogenemia with the lowest; however yet, the role of markers of inflammation in atherosclerosis development and progression is still under debate and few data are available on the role of such markers in the early stages of atherosclero- 
sis, such as in subjects with asymptomatic carotid atherosclerosis.

In contrast to studies on the relationship between hs-CRP and atherosclerosis, Danesh et al. analyzed data from the Reykjavik Study, a prospective cohort study of 19000 middle-aged men and women without a history of MI. hs-CRP levels were measured in blood samples obtained at baseline from as many as 2459 patients who had a nonfatal MI or died of coronary heart disease during the 20-year follow-up and from as many as 3969 controls without a CHD event ${ }^{6)}$.

Patients with an hs-CRP value in the top third (cutoff value, $2.0 \mathrm{mg} / \mathrm{L}$ ) had an unadjusted relative risk of CHD of 1.92, as compared with patients whose values were in the bottom third. However, after adjusting for risk factors such as smoking status, blood pressure, body-mass index, and total cholesterol level, the odds ratio was reduced to 1.45 . This, they point out, is much lower than the odds ratios from previous studies (which have given estimates of around 2.0). In addition, the s-hCRP odds ratio was much lower than that for established risk factors such as increased cholesterol concentration and cigarette smoking.

Regarding firbrinogen, Danesh et al. showed a moderate association between the usual plasma fibrinogen level and the risks of cardiovascular events, stroke, other vascular mortality, and nonvascular mortality in a wide range of circumstances in healthy middle-aged adults. The author concluded that assessment of any causal relevance of elevated fibrinogen levels to disease requires additional research.

However, Ridker takes issue with these statements. He commented to heartwire that the current paper "confirms exactly what we have been saying for years, namely, that hs-CRP is a strong, independent predictor of heart-disease risk even after adjustment for all other known coronary risk factors. In fact, in the new data, the predictive value of hs-CRP is exactly the same as that of high blood pressure and almost as large as that of smoking. So unless one is going to argue that high blood pressure and smoking don't matter, then it is now completely clear that hs-CRP is a major and important risk factor for heart disease. After all, this is the 22nd study of hs-CRP and every single one has been positive".

\section{Inflammation and Carotid Atherosclerosis: Data from Clinical Studies}

Several prospective studies have demonstrated the association between IMT and the occurrence of cardio- and cerebro-vascular events ${ }^{7-9)}$ and recent studies suggest that patients with abnormal IMT should be treated more aggressively than those with normal $\mathrm{IMT}^{10)}$; therefore, measurement of carotid artery IMT may represent a more powerful predictor of cardiovascular events than traditional risk factors. The Mannheim Carotid Intima-Media Thickness Consensus recommends the following definitions for ultrasound characterization of IMT and atherosclerotic plaque: (1) IMT is a double-line pattern visualized by echotomography on both walls of the CCAs in a longitudinal image. It is formed by two parallel lines, which consist of the leading edges of two anatomical boundaries: the lumen-intima and media-adventitia interfaces; (2) Plaque is a focal structure encroaching into the arterial lumen by at least $0.5 \mathrm{~mm}$ or $50 \%$ of the surrounding IMT value, or demonstrates a thickness of $1.5 \mathrm{~mm}$ as measured from the media-adventitia interface to the intima-lumen interface ${ }^{11)}$.

Over the last decade, researches in many laboratories have begun to unravel the association of the inflammatory cascade with the atherosclerotic process. Studies have examined various aspects of the immune system, including adhesion molecules (ICAM-1 and VCAM-1, E-selectin and P-selectin), cytokines (interleukin-6, tumor necrosis factor-alpha) and other acute phase reactants, such as fibrinogen and serum amyloid A. From these inflammatory bio-markers, CRP and fibrinogen emerged as the best clinical tool for cardiovascular risk detection. Regarding CD40, this marker is constantly expressed on the surface of smooth muscle cells, endothelial cells, macrophages and immune cells. Its ligand (CD40L) exists in a soluble form $(s \mathrm{CD} 40 \mathrm{~L})$ and as a transmembrane protein. It is expressed by T-lymphocytes and activated platelets, proving once more the link between inflammation and coagulation in atherosclerosis. Elevated levels of both forms have been found in atheromatous plaques. We recently found ${ }^{12)}$ increased circulating interleukin-6, CD40 ligand, and CRP in patients with asymptomatic carotid lesions, and on multivariate analysis, only sCD40 ligand above the median predicted the risk of cardiovascular events. This is consistent with the finding that high CD40 ligand indicates an increased risk of coronary events.

We included in a prospective 5-years follow-up study a group of patients with asymptomatic carotid intima-media thickness, evaluating at baseline all the established traditional cardiovascular risk factors as well as levels of CRP and fibrinogen and the seropositivity to helicobacter pylori, chlamydia pneumoniae and cytomegalovirus ${ }^{13)}$. Preliminarly, we found that at baseline the increment in quintiles of hs-CRP concentrations was significantly associated with smoking, a family history of CAD, dyslipidemia, plasma fibrino- 


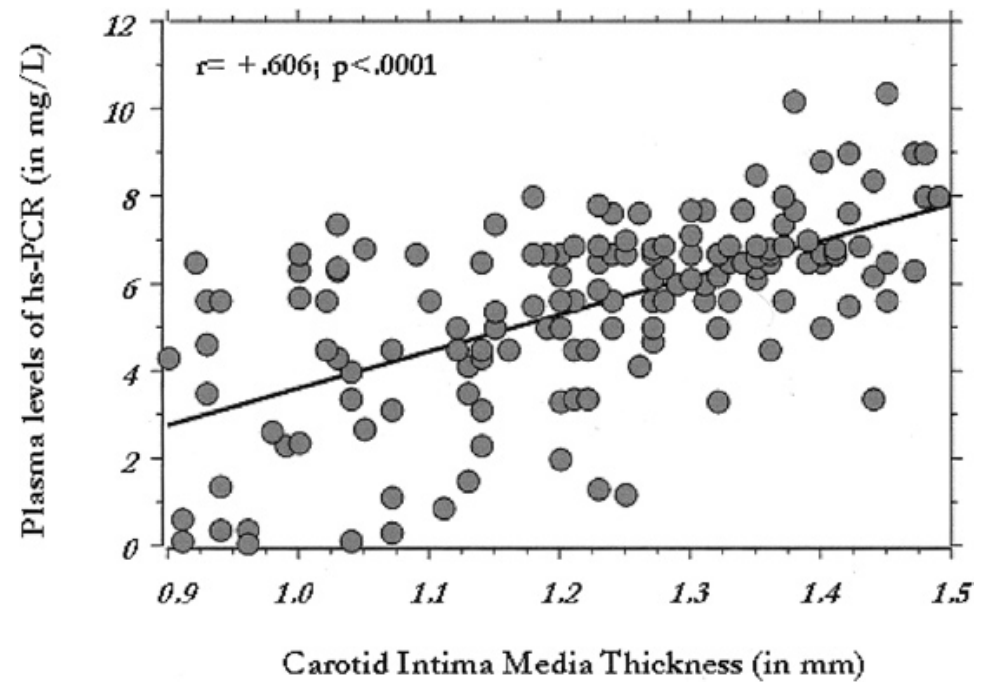

Fig. 2. Box plots (median, 10\%, 25\%, 75\%, 90\%, single values) of plasma hs-HS-CRP levels in patients with $(n=122)$ and without $(n=28)$ clinical events, as registered in the 5-year follow-up.

(Rizzo M et al. Journal of Investigative Medicine, 2008; 56: 32-40)

gen concentrations and seropositivity for chlamydia pneumoniae (non-significant associations were also found with the seropositivity for helicobacter pylori and cytomegalovirus). These findings suggest that elevated hs-CRP plasma levels may represent in this category of patients a good marker of both infection and inflammation. In addition, at the end of follow-up, the increment in quintiles of hs-CRP concentrations was significantly associated with ischemic stroke, AMI, cardiovascular or cerebrovascular death and elevated hs-CRP levels showed a predictive role for cerebro- and cardio-vascular events in both univariate and multivariate analysis. These findings highlight the role of hs-CRP in patients with early stages of atherosclerosis beyond traditional established cardiovascular risk factors and we have further confirmed such data in a subgroup of subjects with hypertension and subclinical atherosclerosis ${ }^{14)}$ (Fig. 2).

Schlager et al. have also shown that hs-CRP levels may predict morphological progression of carotid disease and clinical progression of atherosclerosis in the coronary and cerebrovascular vessel area ${ }^{15)}$.

Low HDL-cholesterol concentrations are associated with increased cardiovascular risk ${ }^{16-17)}$ and international guidelines agree to recommend their therapeutical modulation as one of the primary targets to reduce such risk ${ }^{18)}$. In addition, recent evidence suggests that HDL may aggravate the atherosclerotic process promoting inflammation: HDL are antiinflammatory in the absence of inflammation but can become proinflammatory in the presence of atherosclerosis ${ }^{19)}$. However, no studies have so far directly investigated the cardiovascular outcome in subjects with low HDL-cholesterol and subclinical carotid atherosclerosis and this limits the utility of information we have on this category of high-risk subjects; in fact, based on the available evidence, it cannot be excluded that lower HDL-cholesterol levels may potentially accelerate the progression from subclinical lesions to clinical events.

Therefore, we included in a prospective 5-year follow-up study a group of subjects with low HDLcholesterol concentrations and subclinical carotid atherosclerosis, evaluating at baseline all the established traditional cardiovascular risk factors as well as levels of hs-CRP and fibrinogen. Consistent with the hypothesis that low HDL-cholesterol seems to promote inflammation, we preliminarily found a significant inverse relationship between HDL-cholesterol levels and fibrinogen concentrations, but no association was found with hs-CRP levels. No associations were found between lower HDL-cholesterol and all traditional established cardiovascular risk factors, including hs-CRP and fibrinogen levels, consistent with the knowledge that low HDL-cholesterol levels are mainly genetically determined ${ }^{20)}$. At the end of the follow-up we found that patients with cardio- and cerebro-vascular events showed a higher prevalence of elevated fibrinogen levels and in multivariate analysis this marker of inflammation showed an independent 
predictive role. These findings suggest that familial unfavourable genetic patterns may be associated with increased vascular risk in these subjects, highlighting the role of inflammation, particularly of fibrinogen.

Sabeti et al. ${ }^{21)}$ found in 1268 consecutive patients without recent (12 months) symptoms from cerebrovascular disease that adjusted hazard ratios for atherosclerosis progression with increasing quartiles of baseline fibrinogen were $1.83(p=0.037), 2.09$ ( $p=0.008)$, and $2.45(p=0.002)$, respectively, compared with the lowest quartile. Fibrinogen at follow-up also was associated with progressive disease $(p=0.004)$. Elevated fibrinogen, reflecting the level of inflammatory activity, is associated with progression of carotid atherosclerosis.

Another study demonstrated in subjects with carotid atherosclerosis that fibrinogen was an independent risk factor for cardiovascular disease. In this study, markers of inflammation, hs-C-reactive protein (hs-CRP) and leukocytes, and endothelial perturbation (von Willebrand factor, vWF) were measured in 135 subjects. All individuals underwent a complete clinical examination and lipid measurements (cholesterol and its fractions HDL and LDL and triglycerides). Carotid IMT was measured by B-mode ultrasound in the common carotid artery. The authors found a strong positive relationship between plasma fibrinogen and carotid IMT using a univariate model $(p<0.01)$. Fibrinogen also correlated positively with age, BMI, arterial systolic pressure, cholesterol, cholesterol-LDL, smoking, hs-CRP and vWF $(p<0.01)$. In multivariate analysis, the association of fibrinogen with carotid IMT remained significant $(p<0.01)$ after adjustment for all parameters analyzed. In a population sample of adults without clinically overt atherosclerotic disease, elevated fibrinogen was related to carotid IMT independent of a wide range of important confounding variables ${ }^{22}$. Notably, meta-analyses have shown a strong association between even modest increases in fibrinogen and future cardiovascular events ${ }^{23,24)}$.

Recently, Baldassare et al. ${ }^{25)}$ have shown in a meta-analysis that despite the marked heterogeneity of results presented in the literature, a positive association between carotid intima media thickness (C-IMT) and plasma levels of C-reactive protein (hs-CRP) or fibrinogen may exist. Funnel plot analyses suggested the absence of an important publication bias. The meta-analysis showed that gender, non-insulin-dependent diabetes mellitus (NIDDM) and hypercholesterolemia influence the association between C-IMT and hs-CRP. Blood pressure and hypercholesterolemia influence the association between C-IMT and fibrino- gen. For all other soluble markers considered, the number of groups was too small for this kind of statistical consideration. The authors affirmed that only hs-CRP and fibrinogen seem to be unequivocally related to C-IMT. For all other soluble markers considered, no clear-cut conclusions can be drawn. This is consistent with our previous findings in subjects with baseline asymptomatic carotid lesions ${ }^{26}$.

Elevated levels of inflammatory biomarkers likely show the presence of multiple vulnerable lesions, thus identifying a "vulnerable patient" with several coexisting high-risk lesions in different arterial segments ${ }^{27,28)}$. Rothwell et al..$^{29)}$ demonstrated a systemic predisposition to irregularity and rupture of atherosclerotic plaque independently of traditional vascular risk factors in a large series of patients with carotid stenosis. Elevation of hs-CRP and serum amyloid A indicates enhanced inflammation and may help to identify patients generally at highrisk for morphological and clinical progression of atherosclerotic disease. The concept of identifying vulnerable patients who are susceptible to early cardiovascular events seems appealing and measurement of inflammatory biomarkers may be a potent adjunctive tool for this purpose. In this context it seems particularly interesting that hs-CRP was predictive for cardiovascular events in all investigated subgroups, independently of traditional risk factors and baseline extent of the disease, suggesting the clinical utility of this biomarker adjunctive to conventional clinical risk factors.

\section{Is there Clinical Evidence that Inflammation can be Modified by Preventive Therapies?}

The first data to link the utility of hs-CRP as a marker of inflammation with potential utility in targeting statin therapy emerged from the Cholesterol and Recurrent Events (CARE) trial, a secondary prevention study in which elevated hs-CRP levels correlated with a significantly increased risk of recurrent coronary events. The CARE investigators ${ }^{30}$ also reported that random allocation to pravastatin lowered hs-CRP levels in a manner unrelated to the effect of pravastatin on LDL or HDL cholesterol, data that provided strong evidence that statins may have important anti-inflammatory effects beyond cholesterol lowering.

The Pravastatin Inflammation/CRP Evaluation (PRINCE) ${ }^{31)}$ study was a community-based prospective trial that included both a primary-prevention branch, in which 1702 men and women without a prior history of cardiovascular disease were randomized to pravastatin $40 \mathrm{mg} /$ day or a placebo, and a sec- 
ondary-prevention branch, in which 1182 men and women with a history of myocardial infarction, stroke, or arterial revascularization were assigned to openlabel pravastatin $40 \mathrm{mg} /$ day. In patients treated with pravastatin, hs-CRP was significantly reduced from the baseline by $14.7 \%(0.02 \mathrm{mg} / \mathrm{dL})$ in primary prevention and by $14.3 \%(0.02 \mathrm{mg} / \mathrm{dL})$ in secondary prevention at 12 weeks, and by $14.2 \%$ and $13.1 \%$, respectively, at 24 weeks. In a correlational analysis of pravastatin patients, there were minimal associations between 24-week change in hs-CRP and changes in lipid levels. In linear regression analysis, the only significant predictors of change in hs-CRP on a log scale were pravastatin treatment and baseline hs-CRP.

Assessment of hs-CRP was applied to low-risk individuals in the Air Force/Texas Coronary Atherosclerosis Prevention Study (AFCAPS/TexCAPS) ${ }^{32)}$, a randomized, double-blind, placebo-controlled trial of lovastatin in the primary prevention of acute coronary events. In this analysis, AFCAPS/TexCAPS patients were stratified into four groups based on their LDL-C and their hs-CRP levels. Individuals with an LDL-C level above the study median of $149 \mathrm{mg} / \mathrm{dL}$ had a clear benefit from lovastatin regardless of their hs-CRP level. In patients with an LDL-C below $149 \mathrm{mg} / \mathrm{dL}$ but a high hs-CRP level, the event rate with a placebo was just as high as in patients with LDL-C above 149 $\mathrm{mg} / \mathrm{dL}$ and, most interestingly, the efficacy of lovastatin was high. In marked contrast, individuals with a below-median LDL-C and a below-median hs-CRP level had very low event rates, and there was no demonstrable efficacy of lovastatin therapy overall. Thus, these data suggest that the combination of hs-CRP screening with LDL-C screening might well provide an improved method for predicting the efficacy of statin therapy in primary prevention.

In the Myocardial Ischemia Reduction with Aggressive Cholesterol Lowering (MIRACL) study ${ }^{33)}$, the authors measured plasma levels of hs-CRP, serum amyloid A (SAA), and interleukin 6 (IL-6) in 2402 subjects enrolled. Subjects with unstable angina or non-Q-wave myocardial infarction were randomized to atorvastatin $80 \mathrm{mg} / \mathrm{d}$ or a placebo within 24 to 96 hours of hospital admission and treated for 16 weeks. All three markers were markedly elevated at randomization and declined over the 16 weeks in both treatment groups. Compared with the placebo, atorvastatin significantly reduced hs-CRP, $-83 \%$ versus $-74 \%$ $(p<0.0001)$ and SAA, $-80 \%$ versus $-77 \%(p<0.0006)$ but not IL-6, $-55 \%$ versus $-53 \%(p<0.3)$. Reductions in hs-CRP and SAA were observed in patients with unstable angina and non-Q-wave myocardial infarction, with initial LDL cholesterol $<3.2$ or $\leq 3.2$ $\mathrm{mmol} / \mathrm{L}$ (125 mg/dL). By 16 weeks, hs-CRP was 34\% lower with atorvastatin than with a placebo. In conclusion, intensive lipid lowering with high-dose atorvastatin potentiated the resolution of inflammation after acute coronary syndrome, as reflected by substantially lower levels of hs-CRP and SAA at 16 weeks compared with placebo. These findings support the anti-inflammatory effect of high dose statin therapy in patients with acute coronary syndrome.

The Reversal of Atherosclerosis with Aggressive Lipid Lowering (REVERSAL) trial ${ }^{34)}$ compared the standard lowering of LDL-cholesterol with pravastatin $40 \mathrm{mg} /$ day with the intense lowering of LDL-cholesterol with atorvastatin $80 \mathrm{mg} / \mathrm{day}$ on atheroma volume in patients with coronary artery disease, and showed that the atheroma progressed by $2.7 \%$ in the pravastatin group, and remained unchanged in the atorvastatin group. At 18 months follow-up, hs-CRP levels were reduced from a baseline level of $2.8 \mathrm{mg} / \mathrm{L}$ to $1.8 \mathrm{mg} / \mathrm{L}$ by atorvastatin, whereas pravastatin had little effect and there was a good correlation between both the ultrasonographic progression of disease and the reduction in hs-CRP levels.

The PROVE IT-TIMI 22 trial $^{35)}$ compared the relative efficacy of pravastatin $40 \mathrm{mg}$ and atorvastatin $80 \mathrm{mg}$ daily to reduce LDL-C and hs-CRP among 3,745 patients with acute coronary syndrome. A total of 1,018 participants $(27.1 \%)$ achieved the dual goals of LDL-C $<70 \mathrm{mg} / \mathrm{dL}$ and HS-CRP $<2 \mathrm{mg} / \mathrm{L}$. After adjustment for age, gender, smoking, diabetes, hypertension, obesity, and HDL-C, these individuals had a $28 \%$ lower risk of recurrent myocardial infarction or vascular death. Of those who achieved dual goals, $80.6 \%$ received atorvastatin $80 \mathrm{mg}$, while $19.4 \%$ received pravastatin $40 \mathrm{mg}(p<0.001)$. Only $11 \%$ allocated to pravastatin treatment and $44 \%$ allocated to atorvastatin achieved the goals of LDL-C $<70$ $\mathrm{mg} / \mathrm{dL}$ and hs-CRP $<2 \mathrm{mg} / \mathrm{L}$, and only $5.8 \%$ allocated to pravastatin $40 \mathrm{mg}$ and $26.1 \%$ allocated to atorvastatin $80 \mathrm{mg}$ reached the even lower goals of LDL-C $<70 \mathrm{mg} / \mathrm{dL}$ and HS-CRP $<1 \mathrm{mg} / \mathrm{L}$. Thus, both the REVERSAL and PROVE-IT studies support the concept "the lower, the better"; however, they do not enable the independent and interdependent effects of statins on LDL cholesterol and the process of arterial inflammation to be disentangled.

The $\mathrm{A}$ to $\mathrm{Z}$ trial is an international trial consisting of 2 overlapping phases ${ }^{36}$. Phase A was an openlabel trial comparing enoxaparin with unfractionated heparin in patients with non-ST-elevation acute coronary syndrome (ACS) who were treated with tirofiban and aspirin. Phase $\mathrm{Z}$ is a double-blind trial comparing two statin regimens, $40 \mathrm{mg} / \mathrm{d}$ simvastatin for 1 month 


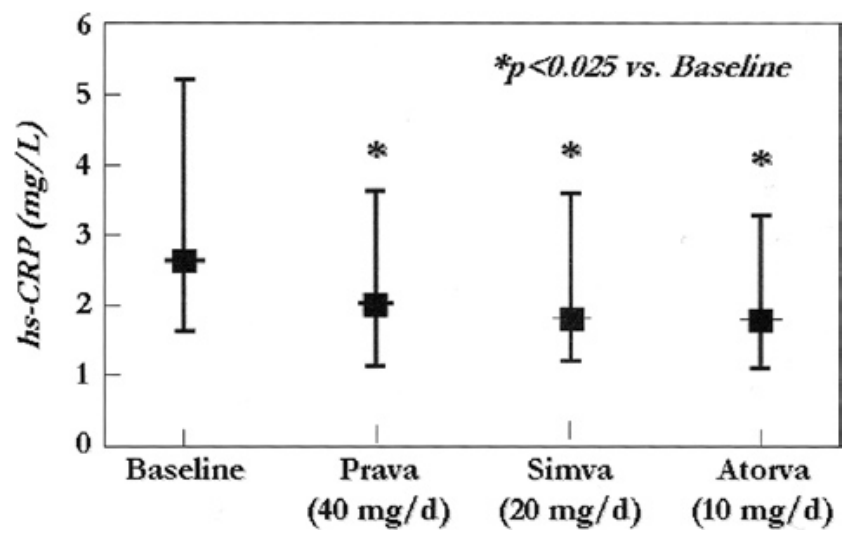

Fig. 3. Effect of Statin Therapy on hs-HS-CRP Levels at 6 Weeks.

(Jialal I et al. Circulation, 2001; 103: 1933-1935)

followed by $80 \mathrm{mg} / \mathrm{d}$ in 2265 patients compared with 2232 patients with ACS receiving a placebo for 4 months followed by $20 \mathrm{mg} / \mathrm{d}$ simvastatin. Among patients in the placebo plus simvastatin group, the median LDL-cholesterol level achieved while taking a placebo was $122 \mathrm{mg} / \mathrm{dL}(3.16 \mathrm{mmol} / \mathrm{L})$ at $1 \mathrm{month}$ and $77 \mathrm{mg} / \mathrm{dL}(1.99 \mathrm{mmol} / \mathrm{L})$ at 8 months while taking $20 \mathrm{mg} / \mathrm{d}$ simvastatin. Among patients in the simvastatin-only group, the median LDL cholesterol level achieved at 1 month while taking $40 \mathrm{mg} / \mathrm{d}$ simvastatin was $68 \mathrm{mg} / \mathrm{dL}(1.76 \mathrm{mmol} / \mathrm{L})$, and was $63 \mathrm{mg} / \mathrm{dL}$ $(1.63 \mathrm{mmol} / \mathrm{L})$ at 8 months while taking $80 \mathrm{mg} / \mathrm{d}$ simvastatin. A total of 343 patients $(16.7 \%)$ in the placebo plus simvastatin group experienced the primary endpoint compared with 309 (14.4\%) in the simvastatin-only group ( $40 \mathrm{mg} / 80 \mathrm{mg}$ ). No difference was evident during the first 4 months between groups for the primary endpoint, but from 4 months through the end of the study the primary endpoint was significantly reduced only in the simvastatin group $(p=0.02)$. In contrast with the PROVE IT study, C-reactive protein concentrations in the $\mathrm{A}$ to $\mathrm{Z}$ trial did not differ between treatment groups at 30 days despite marked differences in LDL-cholesterol levels.

In the $A$ to $Z$ trial, simvastatin therapy achieved final hs-CRP levels very similar to those achieved by atorvastatin $80 \mathrm{mg}$ in the PROVE-IT study. In contrast with the PROVE IT study, however, the C-reactive protein concentrations in the $\mathrm{A}$ to $\mathrm{Z}$ trial did not differ between treatment groups at 30 days despite marked differences in LDL cholesterol levels. The lack of a concurrent anti-inflammatory effect may also have contributed to the delayed treatment effect that was observed. Patients in the aggressive simvastatin arm of the $A$ to $Z$ trial were not titrated up to 80 $\mathrm{mg} / \mathrm{d}$ simvastatin until after the first month. It is possible that more intensive therapy is required immediately after the onset of ACS during the period of greatest clinical instability to achieve a more rapid clinical benefit. The effects of each statin have been studied on the reduction of hs-CRP levels ${ }^{37)}$. Median percent reduction in hs-CRP did not differ significantly among statins; atorvastatin reduced hs-CRP by a median of $28.3 \%$, pravastatin by $20.3 \%$, and simvastatin by $22.8 \%$. With the respective statins, hs-CRP was reduced in $81.8 \%, 72.7 \%$, and $81.8 \%$ of patients; hs-CRP was reduced with all three statins in $54.6 \%$ of patients. Changes in the hs-CRP level were not significantly correlated with changes in LDL-C or HDL-C but was correlated with triglyceride $(r=0.59, p=0.005)$.

The combined predictive value of lipid and hs-CRP levels in mortality was evaluated in a prospective study of 985 patients with severe coronary artery disease, defined as at least $70 \%$ stenosis in at least 1 coronary artery or a primary branch; 109 patients (11\%) died during the mean 3.0-year follow-up ${ }^{38)}$. In Cox regression analyses, baseline levels of total cholesterol, LDL-C, and HDL-C and the total cholesterol HDL-C ratio were not predictive of mortality, but the hs-CRP level was independently predictive; patients with hs-CRP in the first tertile $(<1.2 \mathrm{mg} / \mathrm{dL})$ had a mortality rate of $5 \%$, compared with $13 \%$ in the second tertile $(1.2-1.7 \mathrm{mg} / \mathrm{dL} ; p=0.0009)$ and $15 \%$ in the third tertile $(>1.7 \mathrm{mg} / \mathrm{dL} ; p=0.0001)$. The study also evaluated the effect of statin therapy on mortality in patients across tertiles of hs-CRP. In overall patients, prescription of a statin was associated with improved mortality (95\% confidence interval CI) $0.20-0.78$; $p=0.002) ; 172$ patients (19\%) were prescribed statin therapy, of which $63 \%$ were prescribed simvastatin, $15 \%$ atorvastatin, $13 \%$ pravastatin, $5 \%$ lovastatin, and $4 \%$ fluvastatin.

The METEOR trial investigated whether rosuvastatin therapy could slow the progression or even cause regression of carotid intima-media thickness (CIMT). The study was a randomized, double-blind, placebo-controlled trial comparing treatment with 40 $\mathrm{mg} /$ day rosuvastatin with a placebo in 984 individuals, randomized in a 5:2 ratio. Subjects included were chosen for low risk, with either age as the only risk factor or with a 10-year Framingham risk score of less than $10 \%$. All had mild to moderate CIMT thickening, with a maximum IMT of at least $1.2 \mathrm{~mm}$ at a single site and less than $3.5 \mathrm{~mm}$ at all sites. Subjects with one risk factor had to have an LDL level of less than $190 \mathrm{mg} / \mathrm{dL}$ and those with multiple risk factors had to have an LDL level of less than $160 \mathrm{mg} / \mathrm{dL}$. LDL levels showed a mean reduction of $49 \%$ in the 
rosuvastatin group, declining from $155 \mathrm{mg} / \mathrm{dL}$ to 78 $\mathrm{mg} / \mathrm{dL}$, a statistically significant reduction vs placebo. HDL increased with rosuvastatin by $8 \%$ with treatment. At two years, treatment with rosuvastatin was associated with a statistically significant reduction in the rate of progression of carotid IMT both overall and for individual carotid segments, while the placebo group showed progression; however, there was no regression of the atherosclerosis burden with treatment in this trial ${ }^{39)}$.

Statin therapy appeared to eliminate the excess mortality associated with increased hs-CRP; among patients on statin therapy, mortality was similar across hs-CRP tertiles, whereas in patients without prescribed statins, mortality increased markedly with increasing tertiles of HS-CRP levels. Evidence of a dual mechanism of benefit with statins, lipid lowering and a reduction in inflammation, has important implications for current and future treatment of atherosclerosis. Current guidelines emphasize the use of lipidlowering therapies to reach target levels of LDL cholesterol, non-HDL cholesterol, or both; however, individual agents differ in their ability to reduce the levels of inflammatory biomarkers. The provocative question is that the effects of statins on hs-CRP, as well as LDL cholesterol, should be considered in decisions regarding therapy. Standard preventive therapies, such as aspirin, have been shown to have important effects on the inflammatory process.

The Physicians' Health Study ${ }^{40)}$, a randomized, double-blind, placebo-controlled trial of low-dose aspirin in the prevention of first myocardial infarction, showed a risk reduction in the aspirin group in comparison to the placebo group. As the level of C-reactive protein (hs-CRP) increases, the magnitude of the difference between treatment groups also increases. This suggests directly that aspirin is more efficacious in the prevention of first vascular events in the presence of a heightened inflammatory response than in its absence. These are very intriguing data when we consider that aspirin may have anti-inflammatory effects as well as antiplatelet effects.

The effects of gemfibrozil and ciprofibrate on fibrinogen and hs-CRP were studied in 99 patients with primary hyperlipidemia (type $\Pi \mathrm{a}$ or $\Pi \mathrm{b}$; total cholesterol $\geq 250 \mathrm{mg} / \mathrm{dL})^{41)}$ Patients were randomized to gemfibrozil $600 \mathrm{mg}$ twice daily or to ciprofibrate $100 \mathrm{mg}$ once daily for 12 weeks. Both fibrates significantly reduced plasma fibrinogen levels, with somewhat greater reductions observed in the ciprofibrate group. For both fibrates, the fibrinogen-lowering effect was not associated with the lipid-lowering effect. At 6 weeks, plasma hs-CRP levels were significantly reduced by gemfibrozil but not ciprofibrate, but hs-CRP returned to baseline values at 12 weeks in both treatment groups. Fluvastatin and bezafibrate, alone and in combination, were evaluated ${ }^{42)}$ for their effects on fibrinogen, plasminogen activator inhibitor 1 (PAI-1) and hs-CRP in 333 patients with hyperlipidemia (LDL-C 135-250 mg/dL, triglyceride 180$400 \mathrm{mg} / \mathrm{dL}$ ) and stable angina, prior myocardial infarction, or coronary revascularization. Patients were randomized to receive fluvastatin $40 \mathrm{mg}$, bezafibrate 400 $\mathrm{mg}$, bezafibrate $400 \mathrm{mg}$ + fluvastatin $20 \mathrm{mg}$, or bezafibrate $400 \mathrm{mg}$ + fluvastatin $40 \mathrm{mg}$ for 24 weeks. Plasma fibrinogen was significantly decreased by $9 \%, 14 \%$, and $16 \%$ in the respective bezafibrate treatment groups. PAI-1 and hs-CRP levels did not change with any of the treatment regimens.

\section{Conclusions}

The available prospective data are highly consistent and provide strong evidence that inflammatory markers, such C-reactive protein and fibrinogen, are independent risk factors for coronary disease. Moreover, clinical evidence relating inflammation to vascular risk complements a large body of basic laboratory and experimental studies demonstrating a fundamental role of inflammation in vascular disease.

Recently Goodson N et al. showed in 506 subjects with inflammatory polyarthritis that the CRP concentration at baseline is an important predictor of subsequent death from CAD and is independent of other indicators of disease severity. This supports the theory that CRP may play a direct role in the pathogenesis of $\mathrm{CAD}^{43)}$; however, even if the role of inflammation markers in CAD development and progression has been extensively studied, very few studies have addressed their role in early stages of atherosclerosis, such as in asymptomatic subjects with carotid IMT.

We analyzed in this article the ability of inflammation marker to predict morphological progression of carotid disease and clinical progression of atherosclerosis in the coronary and cerebrovascular vessel area. Reviewing available data it seems that increments of hs-CRP and fibrinogen concentrations are significantly associated with ischemic stroke, AMI, cardiovascular or cerebrovascular death. Baldassare $\mathrm{D}$ et al. have further shown in their meta-analysis that despite the marked heterogeneity of results presented in the literature, a positive association between carotid intima media thickness and plasma levels hs-CRP or fibrinogen may exist. The authors confirmed that only hs-CRP and fibrinogen seem to be unequivocally related to carotid IMT. For all other soluble markers 
considered, no clear-cut conclusions can be drawn ${ }^{25)}$.

In conclusion the strong association of inflammation with outcome and its influence on the pathogenesis of vascular disease saggest the possible role of inflammation as a guide to conventional or antiinflammatory therapy. Definite conclusions cannot be drawn at this point and randomized controlled trials are needed to clarify these issues, but the idea that inflammation markers such as hs-CRP and fibrinogen may be used as a guide to therapy is fascinating and reasonable.

\section{References}

1) Corrado E, Novo S: Role of inflammation and infection in vascular disease. Acta Chir Belg, 2005: 105: 567-579

2) Pearson T, Mensah G, Alexander RW, Anderson JL, Cannon RO, 3rd Criqui M, Fadl Y, Fortmann S, Hong Y, Myers GL, Rifai N, Smith SC Jr, Taubert K, Tracy RP, Vinicor F, Centers for disease control and Prevention; American Heart Association. Markers of Inflammation and Cardiovascular Disease. Application to Clinical and Public Health Practice: A Statement for Healthcare Professionals From the Centers for Disease Control and Prevention and the American Heart Association. Circulation, 2003; 107: 499-511

3) Ridker PM: Inflammation, Infection, and Cardiovascular Risk: How Good Is the Clinical Evidence? Circulation, 1998; 97: 1671-1674

4) Ridker PM: Clinical application of C-reactive protein for cardiovascular disease detection and prevention. Circulation, 2003; 107: 363-369

5) Maresca G, Di Blasio A, Marchioli R, Di Minno G: Measuring plasma fibrinogen to predict stroke and myocardial infarction: an update. Arterioscler Thromb Vasc Biol, 1999; 19: 1368-1377

6) Danesh J, Wheeler JG, Hirschfield GM, Eda S, Eiriksdottir G, Rumley A, Lowe GD, Pepys MB, Gudnason V: $\mathrm{C}$-reactive protein and other circulating markers of inflammation in the prediction of coronary heart disease. $\mathrm{N}$ Engl J Med, 2004; 350: 1387-1397

7) Burke GL, Evans GW, Riley WA, Sharrett AR, Howard G, Barnes RW, Rosamond W, Crow RS, Rautaharju PM, Heiss G: Arterial wall thickness is associated with prevalent cardiovascular disease in middle-aged adults. The Atherosclerosis Risk in Communities (ARIC) Study. Stroke, 1995; 26: 386-391

8) Bots ML, Moons KG, Hollander M, Hoffman A, Koudstaal PJ, Grobbee DE, Breteler MM, Whitman JC: Is carotid intima-media thickness useful in cardiovascular disease risk assessment? The Rotterdam Study. Circulation, 1997; 96: 1432-1437

9) Kitagawa K, Hougaku H, Yamagami H, Hashimoto H, Itoh T, Shimizu Y, Takahashi D, Murata S, Seike Y, Kondo K, Hoshi T, Furukado S, Abe Y, Yagita Y, Sakaguchi M, Tagaya M, Etani H, Fukunaga R, Nagai Y, Matsumoto M, Hori M; OSACA2 Study Group. Carotid intimamedia thickness and risk of cardiovascular events in high- risk patients. Results of the Osaka Follow-Up Study for Carotid Atherosclerosis 2 (OSACA2 Study). Cerebrovasc Dis, 2007; 24: 35-42

10) Bard RL, Kalsi H, Rubenfire MD, Wakefield T, Fex B, Rajagopalan S, Brook RD: Effect of carotid atherosclerosis screening on risk stratification during primary cardiovascular disease prevention. Am J Cardiol, 2004; 93: 10301032

11) Touboul PJ, Hennerici MG, Meairs S, Adams H, Amarenco P, Bornstein N, Csiba L, Desvarieux M, Ebrahim S, Fatar M, Hernandez Hernandez R, Jaff M, Kownator S, Prati P, Rundek T, Sitzer M, Schminke U, Tardif JC, Taylor A, Vicaut E, Woo KS, Zannad F, Zureik M: Mannheim carotid intima-media thickness consensus (2004-2006). An update on behalf of the Advisory Board of the 3rd and 4th Watching the Risk Symposium, 13th and 15th European Stroke Conferences, Mannheim, Germany, 2004, and Brussels, Belgium, 2006. Cerebrovasc Dis, 2007; 23: 75-80

12) Novo S, Basili S, Tantillo R, Falco A, Davì V, Novo G, Corrado E, Davì G: Soluble CD40L and cardiovascular risk in asymptomatic low-grade carotid stenosis. Stroke, 2005; 36: 673-675

13) Rizzo M, Corrado E, Coppola G, Muratori I, Novo S: Prediction of cerebrovascular and cardiovascular events in patients with subclinical carotid atherosclerosis: the role of C-reactive protein. J Investig Med, 2008; 56: 32-40

14) Rizzo M, Corrado E, Coppola G, Muratori I, Mezzani A, Novo G, Novo S: The predictive role of C-reactive protein in subjects with hypertension and subclinical atherosclerosis. Intern Med J 2009 Mar 23. Epub ahead of print)

15) Schlager O, Exner M, Mlekusch W, Sabeti S, Amighi J, Dick P, Wagner O, Koppensteiner R, Minar E, Schillinger M: C-Reactive Protein Predicts Future Cardiovascular Events in Patients With Carotid Stenosis. Stroke, 2007; 38: 1263-1268

16) Grundy SM, Cleeman JI, Daniels SR, Donato KA, Eckel RH, Franklin BA, Gordon DJ, Krauss RM, Savage PJ, Smith SC Jr, Spertus JA, Costa F; American Heart Association; National Heart, Lung, and Blood Institute. Diagnosis and management of the metabolic syndrome: an American Heart Association/National Heart, Lung, and Blood Institute Scientific Statement. Circulation, 2005; 112: 2735-2752

17) Rydén L, Standl E, Bartnik M, Van den Berghe G, Betteridge J, de Boer MJ, Cosentino F, Jönsson B, Laakso M, Malmberg K, Priori S, Ostergren J, Tuomilehto J, Thrainsdottir I, Vanhorebeek I, Stramba-Badiale M, Lindgren P, Qiao Q, Priori SG, Blanc JJ, Budaj A, Camm J, Dean V, Deckers J, Dickstein K, Lekakis J, McGregor K, Metra M, Morais J, Osterspey A, Tamargo J, Zamorano JL, Deckers JW, Bertrand M, Charbonnel B, Erdmann E, Ferrannini E, Flyvbjerg A, Gohlke H, Juanatey JR, Graham I, Monteiro PF, Parhofer K, Pyörälä K, Raz I, Schernthaner G, Volpe M, Wood D; Task Force on Diabetes and Cardiovascular Diseases of the European Society of Cardiology (ESC); European Association for the Study of Diabetes (EASD). Guidelines on diabetes, pre-diabetes, and cardiovascular diseases: executive summary. The Task Force on Diabetes and Cardiovascular Diseases of the European 
Society of Cardiology (ESC) and of the European Association for the Study of Diabetes (EASD). Eu Heart J, 2007; 28: $88-136$

18) National Cholesterol Education Program (NCEP). Expert Panel on Detection, Evaluation, and Treatment of High Blood Cholesterol in Adults (Adult Treatment Panel III). Third Report of the National Cholesterol Education Program (NCEP) Expert Panel on Detection, Evaluation, and Treatment of High Blood Cholesterol in Adults (Adult Treatment Panel III) final report. Circulation, 2002; 106: 3143-3421

19) Navab M, Anantharamaiah GM, Reddy ST, Van Lenten BJ, Ansell BJ, Fogelman AM: Mechanisms of disease: proatherogenic HDL--an evolving field. Nat Clin Pract Endocrinol Metab, 2006; 2: 504-511

20) Rizzo M, Corrado E, Coppola G, Muratori I, Novo G, Novo S: Prediction of cardio- and cerebro-vascular events in patients with subclinical carotid atherosclerosis and low HDL-cholesterol. Atherosclerosis, 2008; 200: 389-395

21) Sabeti S, Exner M, Mlekusch W, Amighi J, Quehenberger P, Rumpold H, Maurer G, Minar E, Wagner O, Schillinger M: Prognostic Impact of Fibrinogen in Carotid Atherosclerosis: Nonspecific Indicator of Inflammation or Independent Predictor of Disease Progression? Stroke, 2005; 36; 1400-1404

22) Martínez-Vila E, Páramo JA, Beloqui $O$, Orbe J, Irimia $P$, Colina I, Monreal I, Benito A, Barba J, Zubieta JL, Diez $\mathrm{J}$ : Independent Association of Fibrinogen with Carotid Intima-Media Thickness in Asymptomatic Subjects. Cerebrovasc Dis, 2003; 16: 356-362

23) Ernst E, Resch KL: Fibrinogen as a cardiovascular risk factor: a meta-analysis and review of the literature. Ann Intern Med, 1993; 118: 956-963

24) Koenig W: Fibrin(ogen) in cardiovascular disease: an update. Thromb Haemost, 2003; 89: 601-609

25) Baldassarre D, De Jong A, Amato M, Werba JP, Castelnuovo S, Frigerio B, Veglia F, Tremoli E, Sirtori CR: Carotid intima-media thickness and markers of inflammation, endothelial damage and hemostasis. Ann Med, 2008; 40: 21-44

26) Corrado E, Rizzo M, Tantillo R, Muratori I, Bonura F, Vitale G, Novo S: Markers of inflammation and infection influence the outcome of patients with baseline asymptomatic carotid lesions: a 5-year follow-up study. Stroke, 2006; 37: 482-486

27) Tracy RP, Lemaitre RN, Psaty BM, Ives DG, Evans RW, Cushman M, Meilahn EN, Kuller LH: Relationship of C-reactive protein to risk of cardiovascular disease in the elderly: results from the Cardiovascular Health Study and the Rural Health Promotion Project. Arterioscler Thromb Vasc Biol, 1997; 17: 1121-1127

28) Ridker PM, Hennekens CH, Buring JE, Rifai N: C-reactive protein and other markers of inflammation in the prediction of cardiovascular disease in women. $\mathrm{N}$ Engl J Med, 2000; 342: 836-843

29) Rothwell PM, Villagra R, Gibson R, Donders R, Warlow CP: Evidence of a chronic systemic cause of instability of atherosclerotic plaques. Lancet, 2000; 355: 19-24

30) Ridker PM, Rifai N, Pfeffer MA, Sacks FM, Moye LA, Goldman S, Flaker GC, Braunwald E: Inflammation,
Pravastatin, and the risk of coronary events after myocardial infarction in patients with average cholesterol levels. Cholesterol and Recurrent Events (CARE) Investigators. Circulation, 1998; 98: 839-844

31) Albert MA, Danielson E, Rifai N, Ridker PM, for the PRINCE Investigators. Effect of statin therapy on C-reactive protein levels: the Pravastatin Inflammation/CRP Evaluation (PRINCE): a randomized trial and cohort study. JAMA, 2001; 286: 64-70

32) Ridker PM, Rifai N, Clearfield M, Downs JR, Weis SE, Miles JS, Gotto AM Jr, for the Air Force/Texas Coronary Atherosclerosis Prevention Study Investigators. Measurement of C-reactive protein for the targeting of statin therapy in the primary prevention of acute coronary events. $\mathrm{N}$ Engl J Med, 2001; 344: 1959-1965

33) Kinlay S, Schwartz GG, Olsson AG, Rifai N, Leslie S, Sasiela WJ, Szarek M, Libby P, Ganz P; for the Myocardial Ischemia Reduction with Aggressive Cholesterol Lowering (MIRACL) Study Investigators High-Dose Atorvastatin Enhances the Decline in Inflammatory Markers in Patients With Acute Coronary Syndromes in the MIRACL Study. Circulation, 2003; 108: 1560-1566

34) Nissen S, Tuzcu EM, Schoenhagen P, Brown BG, Ganz P, Vogel RA, Crowe T, Howard G, Cooper CJ, Brodie B, Grines CL, DeMaria AN, for the REVERSAL Investigators. Effect of Intensive Compared With Moderate LipidLowering Therapy on Progression of Coronary Atherosclerosis. JAMA, 2004; 291: 1071-1080

35) Ridker PM, Morrow D, Rose L, Rifai N, Cannon CP, Braunwald E: Relative Efficacy of Atorvastatin $80 \mathrm{mg}$ and Pravastatin $40 \mathrm{mg}$ in Achieving the Dual Goals of LowDensity Lipoprotein Cholesterol $<70 \mathrm{mg} / \mathrm{dL}$ and C-Reactive Protein $<2 \mathrm{mg} / \mathrm{L}$. An Analysis of the PROVE-IT TIMI-22 Trial. J Am Coll Cardiol, 2005; 45: 1644-1648

36) de Lemos JA, Blazing MA,Wiviott SD, Lewis EF, Fox KA, White HD, Rouleau JL, Pedersen TR, Gardner LH, Mukherjee R, Ramsey KE, Palmisano J, Bilheimer DW, Pfeffer MA, Califf RM, Braunwald E, for the A to Z Investigators. Early Intensive vs a Delayed Conservative Simvastatin Strategy in Patients with Acute Coronary Syndromes Phase $Z$ of the A to Z Trial. JAMA, 2004; 292: 1307-1316

37) Jialal I, Stein D, Balis D, Grundy SM, Adams-Huet B, Devaraj S: Effect of hydroxymethyl glutaryl coenzyme a reductase inhibitor therapy on high sensitive C-reactive protein levels. Circulation, 2001; 103: 1933-1935

38) Horne BD, Muhlestein JB, Carlquist JF, Bair TL, Madsen TE, Hart NI, Anderson JL. Statin therapy, lipid levels, $\mathrm{C}$-reactive protein and the survival of patients with angiographically severe coronary artery disease. J Am Coll Cardiol, 2000; 36: 1774-1780

39) Crouse JR 3rd, Raichlen JS, Riley WA, Evans GW, Palmer MK, O'Leary DH, Grobbee DE, Bots ML; METEOR Study Group. Effect of rosuvastatin on progression of carotid intima-media thickness in low-risk individuals with subclinical atherosclerosis: the METEOR Trial. JAMA, 2007; 297: 1344-1353

40) Ridker PM, Cushman M, Stampfer JS, Tracy RP, Hennekens $\mathrm{CH}$ : Inflammation, Aspirin, and the Risk of Cardiovascular Disease in Apparently Healthy Men. N Engl J 
Med, 1997; 336: 973-979

41) de Maat MP, Knipscheer HC, Kastelein JJ, Kluft C: Modulation of plasma fibrinogen levels by ciprofibrate and gemfibrozil in primary hyperlipidemia. Thromb Haemost, 1997; 77: 75-79

42) Cortellaro M, Cofrancesco E, Boschetti C, Cortellaro F, Mancini M, Mariani M, Paoletti R, Effects of fluvastatin and Bezafibrate combination on plasma fibrinogen, t-plasminogen activator inhibitor and $\mathrm{C}$ reactive protein levels in coronary artery disease patients with mixed hyperlipidemia (FACT study) Fluvastatin alone and in combination treatment. Thromb Haemost, 2000; 83: 549-553

43) Goodson NJ, Symmons DP, Scott DG, Bunn D, Lunt M, Silman AJ: Baseline levels of C-reactive protein and prediction of death from cardiovascular disease in patients with inflammatory polyarthritis: a ten-year followup study of a primary care-based inception cohort. Arthritis Rheum, 2005; 52: 2293-2299 